\title{
Sex-specific compensatory growth in food-deprived Nile tilapia
}

R.E. Barreto ${ }^{1}$,

P.S.A. Moreira ${ }^{1}$ and

R.F. Carvalho ${ }^{2}$
Departamentos de ${ }^{1}$ Fisiologia and ${ }^{2}$ Morfologia, Instituto de Biociências, Universidade Estadual Paulista, Botucatu, SP, Brasil

\section{Correspondence \\ R.E. Barreto \\ Departamento de Fisiologia \\ IB, UNESP \\ Rubião Jr., s/n \\ 18618-000 Botucatu, SP \\ Brasil \\ Fax: +55-14-6821-3744 \\ E-mail: rbarreto@ibb.unesp.br \\ Publication supported by FAPESP.}

Received June 25, 2002

Accepted January 6, 2003

\begin{abstract}
Female Nile tilapia incubate fertilized eggs in their mouth until they are released as alevins. Consequently, the female may not eat during this period. Thus, it would be expected that female Nile tilapia are more adapted to recovering from fasting than males, which do not display this behavior. To test this hypothesis we conducted an experiment with two groups of fish consisting of 7 males and 7 females each, with one fish per aquarium. The experiment was divided into three phases involving adjustment of the animals to experimental aquaria (0-15th day), fasting (16th-27th day), and refeeding (27th-42nd day). Compensatory growth performance was assessed by specific growth rate, weight, food conversion efficiency and food intake. Food conversion efficiency increased after fasting with a similar rate for both sexes. However, specific growth rate, food intake and weight gain (\%) were significantly higher in males than in females in the refeeding phase. Thus, we conclude that male Nile tilapia can compensate for a fasting period more efficiently than females, refuting our hypothesis. A possible mechanism involved in the greater male compensation is that they presented greater hyperphagia than females, concomitantly with a similar rate of food conversion efficiency for both sexes during refeeding, which would probably be provoking greater growth in males.
\end{abstract}

Key words

- Compensatory growth

- Fasting

- Sex-related growth

- Mouthbrooding fish

- Nile tilapia

- Oreochromis niloticus ......................

\section{Introduction}

Compensatory growth is a phenomenon defined as a phase of rapid growth following food deprivation. This compensatory response has been described for many fish species (1-6), including the Nile tilapia $(7,8)$. Much attention has been focused on the phenomenon of compensatory growth, mainly in commercial fish species, because it is a way to ameliorate fish growth performance, since the compensatory growth can be so intense that fish exhibit a higher growth rate than those continuously fed. This represents a greater fish weight gain, as reported for sunfish by Hayward et al. (9). For this reason, studies have been conducted on the factors that modulate this phenomenon such as duration of food restriction, age, speciesspecific differences (1), previous nutritional status $(1,10,11)$, and grouping $(12,13)$. No study, however, has considered sex-related compensatory growth.

Many investigators have reported that the male tilapia grows more than the female (1418). According to Fryer and Iles (19), the 
greater growth of the male is caused less by behavioral factors than by genetic causes. Ufodike and Madu (20) explained that an anabolism-enhancing effect of androgens causes the greater growth in male tilapia, while Toguyeni et al. (18) highlighted hormonal factors. On the other hand, Schreiber et al. (21) reported that female Nile tilapia reared individually (excluding male territorial aggression) might grow more than males, and explained that the greater male growth is probably caused by behavioral rather than physiological factors. Thus, greater female growth is restricted to particular situations for the Nile tilapia.

In the present study, we looked for another condition in which females would acquire greater growth than males. Nile tilapia (Oreochromis niloticus) is a mouthbrooding cichlid in which the female picks up the fertilized eggs and incubates them in her mouth until they are released as alevins $(22,23)$. In this species, the mouthbrooding period ranges from 10 to 12 days (23), a period during which the female cannot feed (22). Thus, fasting represents a more intense selection pressure for females than for males and, because of this, we may consider fasting to be a more familiar stimulus for females than for males. Therefore, we may expect different organic responses between sexes, since better growth compensatory mechanisms (such as better food conversion efficiency) may have been fixed in Nile tilapia females by sexual selection. Accordingly, we assumed that female Nile tilapia may be more prepared to respond to fasting and may present greater growth than males during this short phase of compensation after a fasting period. This hypothesis was tested in the present study. Since Nile tilapia is the most extensively cultivated cichlid in the world, understanding the factors that modulate compensatory growth in this species is an extremely important goal for aquaculture management. The operational indicators of growth chosen to estimate better compensation were weight, specific growth rate, food conversion efficiency, and food intake, all being well-established indicators of compensatory growth in fish $(1-3,10,24)$.

\section{Material and Methods}

Adult Nile tilapia, Oreochromis niloticus (Linnaeus 1759), were held for about 5 months in a 1200-liter tank (1 fish/4 liters). During this time, the water temperature averaged $24^{\circ} \mathrm{C}$, with continuous aeration through a biological filter. The animals were submitted to a photoperiod of 12-h light:12$\mathrm{h}$ dark, with lights on at 6:00 am and were fed daily.

\section{Experimental design and specific procedures}

Seven males and seven females were chosen by weight $(34.1 \pm 1.2$ and $34.4 \pm 1.6 \mathrm{~g}$, respectively, mean $\pm \mathrm{SD}$ ), and placed in the experimental aquarium ( $40 \times 20 \times 25 \mathrm{~cm})$. The fish were studied completely isolated from one another (1 fish/aquarium). The experiment was divided into three phases involving adjustment of the animals to experimental aquaria (0-15th day), fasting (16th-27th day), and refeeding (28th-42nd day) according to a procedure adapted from Russell and Wootton (2). Twelve days of fasting were scheduled because the duration of the mouthbrooding period in the Nile tilapia varies from 10 to 12 days (see Ref. 23). Fish weight was sampled before and after each experimental phase, for a total of four sample weights. For this procedure each specimen was individually anesthetized by transporting it to a tank containing benzocaine solution $(80 \mathrm{mg} / \mathrm{l})$. Complete fasting was applied because it better resembles the mouthbrood situation, in which females do not feed at all throughout the mouthbrooding period. Moreover, a temporarily restricted feeding may not affect food conversion efficiency (25). Also, Boujard et al. (11) suggested that a higher effect on food conver- 
sion efficiency occurs when fish are exposed to food deprivation instead of a period of food restriction. Hence, the use of complete fasting is more adequate for the induction of the full responses of compensatory growth, i.e., hyperphagia and the increase in both food conversion efficiency and specific growth rate.

Each fish was fed daily at 14:00 $\mathrm{h}$ throughout the experiment, except during the fasting period, with commercial dry pellets for tropical fish (Purina ${ }^{\circledR}$ Ltda., Campinas, SP, Brazil) corresponding to the optimal protein diet (38\%) for Oreochromis, as suggested by James and Sampath (26). The quantity of food provided to each fish was $5 \%$ of their biomass (27).

At each feeding, a known amount of food was added to each aquarium. Uneaten food was collected by siphoning $30 \mathrm{~min}$ later, dried to a constant weight and quantified. Thus, the daily food ingestion for each individual was inferred by calculating the difference between the dry weight of food before and after this handling. The rate of loss of uneaten food was evaluated in six replicates by adding a weighed amount of food to the aquarium containing only water for $30 \mathrm{~min}$, after which uneaten food was collected, dried and reweighed (a procedure based on Qian et al. (5) for the estimate of rate of uneaten food loss). No loss of uneaten food due to leaching or breaking up during the 30-min exposure of food to both water and the slight movement of water caused by the biological filter was detected. Thus, it is unlikely that food intake and food conversion efficiency were overestimated.

During the experiment, the aquarium was equipped with a biological filter, and the water temperature averaged $25.83 \pm 0.22^{\circ} \mathrm{C}$, $\mathrm{pH}$ ranged from 6.6 to 6.9 , water-dissolved oxygen ranged from 5.53 to $6.87 \mathrm{mg} / \mathrm{l}$, and nitrite and ammonia were lower than 0.5 and $0.1 \mathrm{mg} / \mathrm{l}$, respectively. The photoperiod was set from 6:00 to 18:00 h (12-h light:12-h dark).

\section{Calculations and statistical analysis}

The following parameters of growth performance were calculated as described by $\mathrm{Fu}$ et al. (28): specific growth rate $=100\left(\operatorname{lnW}_{\mathrm{f}}\right.$ $\left.\ln \mathrm{W}_{\mathrm{i}}\right) \Delta \mathrm{t}^{-1}$; food conversion efficiency $=100$ $\left(\mathrm{W}_{\mathrm{f}}-\mathrm{W}_{\mathrm{i}}\right) \mathrm{I}^{-1}$; food intake $=100 \mathrm{I} 2 \Delta \mathrm{t}^{-1}\left(\mathrm{~W}_{\mathrm{f}}+\right.$ $\left.\mathrm{W}_{\mathrm{i}}\right)^{-1}$; where $\mathrm{Wf}$ is the final and $\mathrm{Wi}$ the initial weight of the fish, I is the total dry food consumed during each experimental phase, and $\Delta \mathrm{t}$ is the time interval of each experimental phase (see above).

Weight was analyzed by considering the total gross body weight and percent body weight changes throughout the experimental phases.

The parameters assessed here were compared considering the differences between sexes in each experimental phase, using the Mann-Whitney U-test. Also, the within-sex differences throughout the experimental phases were evaluated by the Wilcoxon test (for two time points) or by Friedman's twoway ANOVA followed by Dunnett's multiple comparison test (for three or more time points). These statistical procedures were based on Lehner (29).

\section{Results}

After the first 15 days, both male and female gross body weight increased significantly, followed by a statistically significant decrease immediately after fasting and an increase after refeeding (Figure 1). However, there was no significant difference in

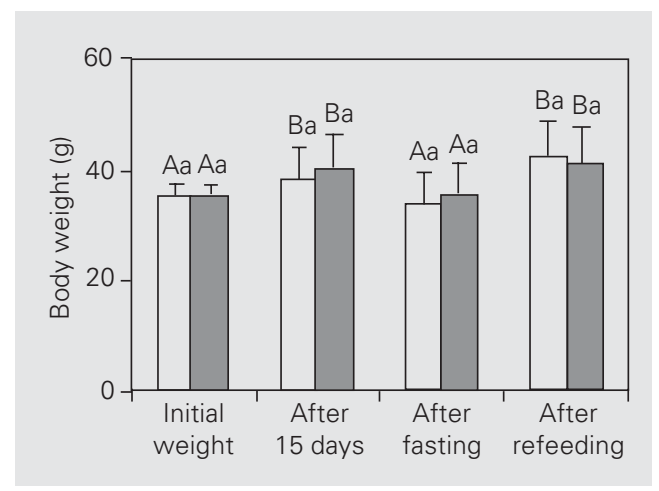

Figure 1. Effect of fasting and refeeding on body weight of Nile tilapia males (open bars) and females (filled bars). Data are reported as means \pm SD. Columns not sharing the same letter are significantly different from each other. Capital letters compare the same sex throughout the experiment $(P<0.001$, Friedman's two-way ANOVA; $N=7$ ), while small letters compare sexes in the same phase $(P=n s$, MannWhitney U-test; $\mathrm{N}=7$ ). 
gross body weight between the male and female groups throughout the experiment (Figure 1). On the other hand, percent body weight gain was higher in males than in females during the refeeding phase (Figure 2 ). The specific growth rate of each sex was

Figure 2. Effect of fasting and refeeding on body weight changes (A) and specific growth rate (B) of male (open bars) and female (filled bars) Nile tilapia. Data are reported as means \pm SD. Columns not sharing the same letter are significantly different from each other. Capital letters compare the same sex throughout the experiment $(P<0.0009$, Friedman's two-way ANOVA; $N=7$ ), while small letters compare sexes in the same phase $(P<0.03$, Mann-Whitney U-test; $N=7$ ).

Figure 3. Effect of fasting and refeeding on food conversion efficiency (A) and feed intake (B) of male (open bars) and female (filled bars) Nile tilapia. Data are reported as means \pm SD. Columns not sharing the same letter are significantly different from each other. Capital letters compare the same sex throughout the experiment $(P<0.03$, Wilcoxon test; $N=7$ ), while small letters compare sexes in the same phase $(P=n s$, MannWhitney U-test; $\mathrm{N}=7$ ).
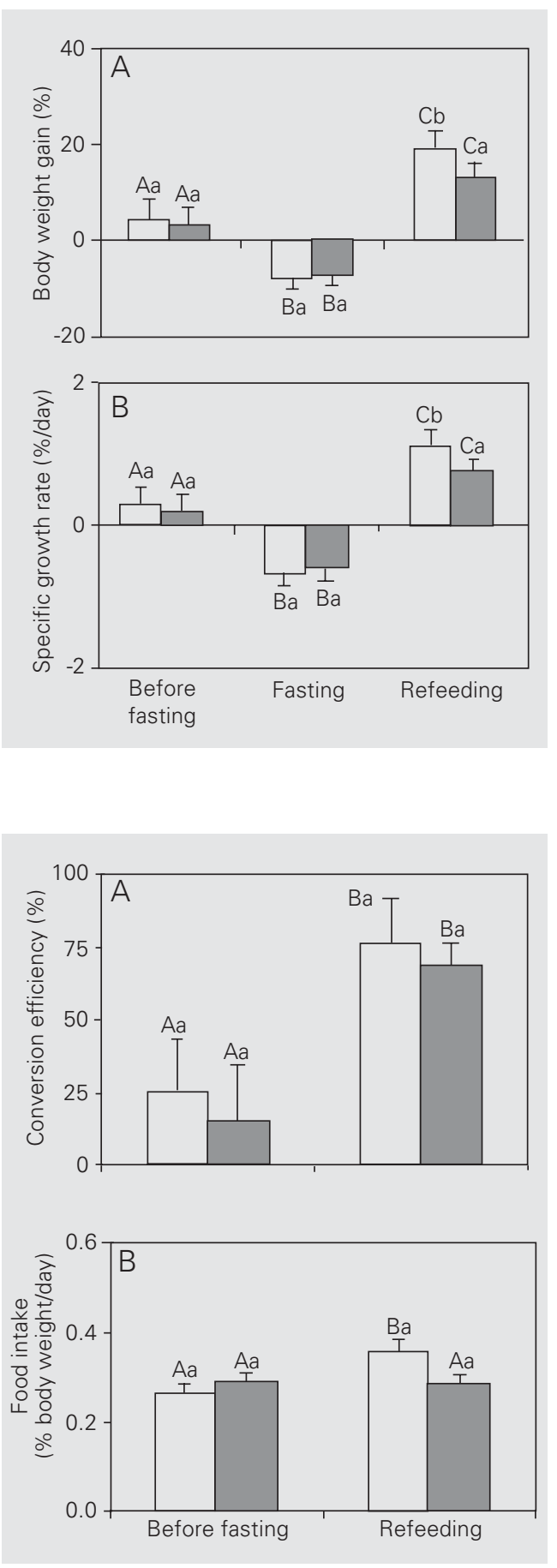

significantly different between phases. Moreover, in the refeeding phase, male specific growth rate was significantly higher than female specific growth rate (Figure 2). Conversion efficiency during the compensation phase was significantly higher in both sexes when compared to the period before fasting, but there was no difference between sexes (Figure 3). Food intake by males during compensation was significantly higher than before fasting, but was not higher than female food intake during the refeeding phase (Figure 3).

\section{Discussion}

Under the present experimental conditions, the parameters of growth performance were affected by food deprivation, indicating that the Nile tilapia displays compensatory growth while refeeding after fasting. Hence, the comparison of compensatory growth between male and female Nile tilapia should be valid and informative.

We observed that sex had a significant influence on compensatory growth. However, some indicators of growth performance studied here were higher in males, showing a higher compensation for fasting compared to females. Therefore, the hypothesis tested in the present study that females should be able to compensate for fasting better than males was refuted.

Food conversion efficiency increased similarly after fasting in the male and female Nile tilapia studied here. Similar results were described in other studies, where fasting generally induced a food conversion increase in mammals and birds (30), as well as in fish $(2,3,5)$. However, these investigators did not consider sex differences. The results presented here indicate that the compensatory response of an increase in food conversion efficiency after fasting is not sex dependent in Nile tilapia.

An increase in food intake is another compensatory mechanism reported in fish 
$(1-3,5)$. In the present study, we observed that only male Nile tilapia presented an increase in food intake after fasting. Thus, hyperphagia in response to fasting in this species depends on sex.

The specific growth rate before and during fasting was similar for the male and female fish studied. However, a significant specific growth rate increase was observed for males during the refeeding phase. Toguyeni et al. (18) reported similar results for the same species, in which males and females expressed a similar specific growth rate at different feeding levels even during starvation. Nevertheless, these investigators did not study the specific growth rate during a refeeding period after fasting. Hence, it may be concluded that specific growth rate is affected by fasting, and that it is sex related in the Nile tilapia.

The mechanisms of compensation explained above indicate that Nile tilapia males can compensate for fasting better than females. Thus, a higher weight gain after the refeeding period for males is expected. Nevertheless, the mean gross weights of male and female Nile tilapia were similar. Probably, no difference was observed between sexes due to the short duration of the refeeding phase, which may have limited the increase in male gross body weight over that of females. However, when weight was analyzed by percentage, it was clear that males had greater growth than females during the refeeding phase. Another consideration is that fish were fed only once a day. This feeding regime probably had no effect in terms of limiting growth, as fish presented compensatory growth, showing that the feeding regime was adequate for fish growth. In fact, they exceeded their initial gross body weight after 15 days of refeeding. Thus, we consider that the feeding regime did not influence our major findings. Had we had a longer period of observation, we would probably have found a difference in gross weight between the sexes.
Greater growth of males over females is very common among cichlids (15,16,31), and this differential growth is related to many factors such as genotype (19), androgen anabolism (20), and hormonal differences (18). Accordingly, selective forces may have provoked a fixation of these features that would contribute to greater male growth performance in cichlid species, possibly due to their behavior, because a greater body size is an important factor for a better execution of some behaviors such as territory defense, competition for females, or nest building (see 31,32). Thus, within this context, considering that fasting has been very frequent in the evolutionary history of female Nile tilapia behavior, it is expected that females would compensate for a fasting period more efficiently than males. However, this was not observed in the present study. Hence, we propose an explanation supported by an argument raised by Russell and Wootton (2). These investigators assume that fish have a genetically predetermined growth trajectory, which is maintained by a homeostatic regulatory mechanism of both appetite and growth performance. Thus, these adjustments (e.g., compensatory growth after fasting) contribute to minimizing the discrepancy between the predetermined and achieved growth trajectory. The Nile tilapia has a very early sexual maturation, with an increase in intermale aggression and dispute for territory and females (33). The time for the recovery of normal growth rate may reflect on body size and thus interfere with some Nile tilapia life processes, such as territorial disputes and social status $(34,35)$. For this reason, a low compensation must suffice for growth requirements of Nile tilapia females, whereas males would require a greater compensation in order to resume their normal growth rate to minimize the decelerating effect of fasting on growth rate. The greater compensatory growth of males might represent a selective advantage in terms of greater body size benefit during intermale competition tasks. 
Finally, a possible mechanism involved in the greater male compensation is that they presented greater hyperphagia than females, concomitantly with a similar rate of food conversion efficiency for both sexes during refeeding (see Figure 3), which would probably induce greater growth in males. However, further experiments should be conducted to improve our understanding of the role of food intake (and also of other mechanisms) in the greater compensation by male Nile tilapia compared to females. In the case of females, a question that may be raised is the possible physiological difference between a brooding Nile tilapia and the fish studied herein. In fact, growth in fish is mainly regulated by the brain neuroendocrine-growth hormone-insulin-like growth factor axis (36). Growth hormone levels in the Nile tilapia tend to increase with the decrease in food levels (18). Similarly, in a related cichlid, the Mozambique tilapia (Oreochromis mossambicus), growth hormone levels may also increase due to fasting, either by brooding or by experimental starvation, but with a different response profile (37). Even so, no significant correlation was found between growth hormone levels and specific growth rate in the Nile tilapia (18). On the other hand, different hormonal levels in estradiol, testosterone, and progesterone may occur between brooding and nonbrooding Nile ti- lapia (38). Nevertheless, no correlation between steroid hormones and food intake or growth was reported for female Nile tilapia (18). Furthermore, $T_{3}$, but not $T_{4}$, decreases due to food restriction in the Nile tilapia (18). However, to our knowledge, there are no data comparing $T_{3}$ and $T_{4}$ responses between brooding and nonbrooding fish. Thus, according to the above considerations, physiological states between brooding female Nile tilapia and the fish used herein possibly did not mask the expected biological results. Even so, the relation among growth and hormonal differences in brooding and nonbrooding female Nile tilapia is a question that should be clarified in future studies.

\section{Acknowledgments}

The authors wish to acknowledge Dr. G.L. Volpato for all background support and some indispensable suggestions for this manuscript, Mr. A.C.B. Tardivo for valuable technical assistance, and especially Dr. A.M.M.C. Gontijo for his contributions to this manuscript and revision of the English text. We are also grateful to Dr. F.A.G. Mello for English revision, to Dr. H.C. Delicio and Dr. M.L.M.V. Paulino for critical analyses and suggestions, and to Dr. M. Dal Pai-Silva for encouraging our research.

\section{References}

1. Miglavs I \& Jobling M (1989). Effects of feeding regime on food consumption, growth rates and tissue nucleic acids in juvenile Arctic charr, Salvelinus alpinus, with particular respect to compensatory growth. Journal of Fish Biology, 34: 947-957.

2. Russell NR \& Wootton RJ (1992). Appetite and growth compensation in the European minnow, Phoxinus phoxinus (Cyprinidae), following short periods of food restriction. Environmental Biology of Fishes, 34: 277-285.

3. Jobling M, Jørgensen EH \& Siikavuopio SI (1993). The influence of previous feeding regime on the compensatory growth response of maturing and immature Arctic charr, Salvelinus alpinus. Journal of Fish Biology, 43: 409-419.

4. Paul AJ, Paul JM \& Smith RL (1995). Compensatory growth in Alaska yellowfin sole, Pleuronectes asper, following food deprivation. Journal of Fish Biology, 46: 442-448.
5. Qian $X$, Cui $Y$, Xiong B \& Yang $Y$ (2000). Compensatory growth, feed utilization and activity in gibel carp, following feed deprivation. Journal of Fish Biology, 56: 228-232.

6. Xie S, Zhu X, Cui Y, Wootton RJ, Lei W \& Yang Y (2001). Compensatory growth in the gibel carp following feed deprivation: temporal patterns in growth, nutrient deposition, feed intake and body composition. Journal of Fish Biology, 58: 999-1009.

7. Mélard C, Baras E \& Despez D (1997). Compensatory growth of Nile tilapia Oreochromis niloticus. In: Fitzsimmons K (Editor), Tilapia Aquaculture. Proceedings of the Fourth International Symposium on Tilapia in Aquaculture, Orlando, FL, USA, November 9-12, 1997.

8. Takagi $Y$ (2001). Effects of starvation and subsequent refeeding on formation and resorption of acellular bone in tilapia, Oreochromis niloticus. Zoological Science, 18: 623-629.

9. Hayward RS, Noltie DB \& Wang N (1997). Use of compensatory 
growth to double hybrid sunfish growth rate. Transactions of the American Fisheries Society, 126: 316-322.

10. Ali M \& Wootton RJ (2000). Pattern of hyperphagia in immature three-spined sticklebacks after short-term food deprivation. Journal of Fish Biology, 56: 648-653.

11. Boujard T, Burel C, Médale F, Haylor G \& Moisan A (2000). Effect of past nutritional history and fasting on feed intake and growth in rainbow trout Oncorhynchus mykiss. Aquatic Living Resources, 13: 129-137.

12. Jobling $M$ (1995). Simple indices for the assessment of the influences of social environment on growth performance, exemplified by studies on Arctic charr. Aquaculture International, 3: 60-65.

13. MacLean A \& Metcalfe NB (2001). Social status, access to food, and compensatory growth in juvenile Atlantic salmon. Journal of Fish Biology, 58: 1331-1346.

14. Brown JM \& Van Someren VD (1953). New fish culture methods for Tilapia in East Africa. Nature, 172: 330-332.

15. Lowe-McConnell R (1958). Observations on the biology of Tilapia nilotica Linné in East African waters. Revue de Zoologie et de Botanique Africaines, 57: 129-170.

16. Palada-de Vera MS \& Eknath AE (1993). Predictability of individual growth rates in tilapia. Aquaculture, 111: 147-158.

17. Dixon D (1994). On the fish farm, boys are best. New Scientist, 143: 18.

18. Toguyeni A, Baroiller JF, Fostier A, Le Bail PY, Khün ER, Mol KA \& Fauconneau B (1996). Consequences of food restriction on shortterm growth variation and plasma circulating hormones in Oreochromis niloticus in relation to sex. General and Comparative Endocrinology, 103: 167-175.

19. Fryer G \& Iles TD (1972). The Cichlid Fishes of the Great Lakes of Africa: Their Biology and Distribution. TFH Publications, Neptune City, NJ, USA.

20. Ufodike EBC \& Madu CD (1986). Effects of methyltestosterone on food utilization and growth in Sarotherodon niloticus fry. Bulletin of the Japanese Society of Scientific Fisheries, 52: 1919-1922.

21. Schreiber S, Focken U \& Becker K (1998). Individually reared female Nile tilapia (Oreochromis niloticus) can grow faster than males. Journal of Applied Ichthyology, 14: 43-47.

22. Maar A, Mortimer MAE \& Van Der Lingen I (1966). Fish Culture in Central East Africa. FAO Publication 53608-66/E.

23. Rothbard S, Solnik E, Shabbath S, Amado R \& Grabie I (1983). The technology of mass production of hormonally sex-inversed ail-male tilapias. In: Fishelson L \& Yaron S (Editors), Tilapia Aquaculture. Proceedings of the First International Symposium on Tilapia in Aquaculture, Nazareth, Israel, May 8-13, 1983.

24. Jobling M \& Koskela J (1996). Interindividual variations in feeding and growth in rainbow trout during restricted feeding and in a subsequent period of compensatory growth. Journal of Fish Biology, 49: 658-667.

25. Kim MK \& Lovell RT (1995). Effect of restricted feeding regimens on compensatory weight gain and body tissue changes in channel catfish Ictalurus punctatus in ponds. Aquaculture, 106: 285-293.

26. James R \& Sampath K (1999). Effects of zeolite reduction of cadmium toxicity in water and a freshwater fish, Oreochromis mossambicus. Bulletin of Environmental Contamination and Toxicology, 62: 222-229

27. Stickney RR (1994). Principles of Aquaculture. Wiley-Interscience, John Wiley and Sons, New York, NY, USA.

28. Fu C, Cui Y, Hung SSO \& Zhu Z (1998). Growth and feed utilization by $\mathrm{F}_{4}$ human growth hormone transgenic carp fed diets with different protein levels. Journal of Fish Biology, 53: 115-129.

29. Lehner PN (1996). Handbook of Ethological Methods. Cambridge University Press, Cambridge, UK.

30. Wilson PN \& Osbourn DF (1960). Compensatory growth after undernutrition in mammals and birds. Biological Reviews, 35: 324-363.

31. Shütz D \& Taborsky M (2000). Giant males or dwarf females: what determines the extreme sexual size dimorphism in Lamprologus callipterus? Journal of Fish Biology, 57: 1254-1265.

32. Sato T (1994). Active accumulation of spawning substrate: a determinant of extreme polygyny in a shell-brooding cichlid fish. Animal Behavior, 48: 669-678.

33. Freitas EG (1999). Investimento reprodutivo e crescimento em machos de tilápia-do-Nilo. Doctoral thesis, Zoologia, Instituto de Biociências, UNESP, Botucatu, SP, Brazil.

34. Fernandes MO \& Volpato GL (1993). Heterogeneous growth in the Nile tilapia: social stress and carbohydrate metabolism. Physiology and Behavior, 54: 319-323.

35. Volpato GL \& Fernandes MO (1994). Social control of growth in fish. Brazilian Journal of Medical and Biological Research, 27: 797-810.

36. Peng C \& Peter RE (1997). Neuroendocrine regulation of growth hormone secretion and growth in fish. Zoological Studies, 36: 79-89.

37. Weber GM \& Grau EG (1999). Changes in serum concentrations and pituitary content of the two prolactins and growth hormone during the reproductive cycle in female tilapia, Oreochromis mossambicus, compared with changes during fasting. Comparative Biochemistry and Physiology, 124C: 323-335.

38. Tacon P, Baroiller JF, Le Bail PY, Prunet P \& Jalabert B (2000). Effect of egg deprivation on sex steroids, gonadotropin, prolactin, and growth hormone profiles during the reproductive cycle of the mouthbrooding cichlid fish Oreochromis niloticus. General and Comparative Endocrinology, 117: 54-65. 